\title{
The Evaluation of the Policy Effect for the Influence of Western Development Drive Policy on the Opening Up of Western China
}

\author{
Nan LI *, Lei WU, Beibei SHI and Rong KANG \\ Northwest University, Xi'an, China; Ininshangbian@163.com; 18904603020@163.com; pgyky412@163.com; \\ kangrong@nwu.edu.cn \\ * Correspondence: lninshangbian@163.com
}

\begin{abstract}
Based on the background of the western development drive policy for 20 years, this paper identifies the net effect of this policy on the regional opening from the perspectives of opening to the outside world and opening to the domestic, and further evaluates and ranks the western provinces' opening to the outside world from the macro perspective, trying to grasp the general situation of the western region's internal and external development. (2) This paper analyzes the net effect of the policy by the method of DID (Differences-in-Differences). After that, a series of robustness tests are carried out, including parallel trend, counterfactual, substitution variable and so on. Entropy method is used in the comprehensive evaluation of provinces. (3) Through regression analysis, this paper finds that the implementation of the western development drive policy has an inhibitory effect on the opening to the outside world in western region, while has a positive role in promoting the opening to domestic. Further research finds that the cause of this result may be the "squeeze effect" of capital. In addition, Sichuan, Chongqing and other regions ranked higher in opening up in the western region, while Qinghai, Ningxia ranked lower.
\end{abstract}

Keywords: western development; policy effect evaluation; opening up; opening to domestic

JEL Classification: C51; O12; O18

\section{Introduction}

The western development drive strategy as an important part of the national modernization strategy originated in 1999. In 1999, "the resolution of the Central Committee of the Communist Party of China on several major issues concerning the reform and development of state-owned enterprises" made it clear for the first time that the western development drive strategy should be carried out in order to transfer the surplus economic development capacity of the eastern coastal areas to the western areas, realize the transformation and upgrading of the industrial structure of the eastern areas, improve the economic and social development level of the western areas, and coordinate the regional economic development. After 20 years development, the western region has made great achievements in economic strength, infrastructure guarantee ability, characteristic advantageous industries and opening economy level. From the perspective of economic aggregate, the GDP of the western region increased from 12.7 trillion yuan to 17.1 trillion yuan in 2013-2017. In terms of economic growth rate, the economic growth of the western region surpassed the eastern region for the first time in 2007, and has been maintained up to now. GDP of the western region maintained an average annual growth rate of $8.8 \%$ from 2013 to 2017. The introduction and implementation of the "the Belt and Road" initiative has brought new opportunities for development in the western region. However, for the western development drive policy, one of its objectives is to improve the level of western development, and for the western development, strengthening foreign exchange is one of the essential ways, so it is very important to evaluate the openness development of Western China. Based on this, this paper attempts to identify the net effect of the policy implementation from the two perspectives of opening to the outside world and opening to the domestic, and accurately evaluate the development of the western 
region in the past 20 years, so as to provide useful policy suggestions for improving the level of regional development.

\section{Literature Review}

The western development drive strategy is one of the most important policies formulated at the beginning of the 21st century in China. Its purpose is to improve the development level of the western region of China and improve the imbalance of regional development in China. Therefore, a lot of research has been done around the western development drive policy. Through combing the existing literature, this paper finds that it mainly focuses on the following three aspects. The first is the study of the relationship between the implementation of the western development drive policy and regional economic growth. Liu Ruiming and Zhao Renjie (2015), Wang Xiaoli et al. (2019) found that the implementation of this policy did not effectively promote the development of regional economy by testing the effect of the western development drive policy on economic growth. In contrast to this conclusion, Ru Shaofeng and Zhou Zikai (2019), Ren Baoping and Zhang Qian (2019), Gan Weiyu et al. (2011), Zhou Duanming et al. (2014), Kong Yang et al. (2018), found that the western development drive policy promoted the economic development of the western region, especially the high-quality development of the regional economy. Based on the economic development situation, Chen Taiming (2017) studied the western development drive strategy from the perspective of welfare, and found that the difference of urban residents' welfare has been improved, but the welfare of farmers has deteriorated in different degrees. In addition, other scholars have identified the net effect of this policy, including Li Hui (2006), Peng Xi and Chen Zhongchang (2016), Tan Zhouling and Cheng Bao (2018). At the same time, some scholars have evaluated the performance of the western development drive strategic, including Cai Huazhou (2002), Zeng Kunsheng (2002), Wei Houkai and Sun Chengping (2004), Lin Jianhua and Ren Baoping (2009),Peng Hui and Zhang Lishu (2009), Wei Houkai and Zhao Yong (2014),Wang Yongjing and Ge Wenfang (2016), Bai Yongxiu and He Hao (2019). Finally, some scholars try to identify the policy effect of the western development drive from the perspective of government intervention, including Bai Yongxiu and Ren Baoping (2000) through the discussion of government functions and positioning, and put forward the necessity of the transformation of government functions under the background of this strategy and market economy. At the same time, some scholars use the method of multiple difference to study the scale change of local government under the background of the implementation of the western development drive strategy, and through the analysis, it is concluded that the implementation of the strategy has expanded the scale of the government, including Shao Chuanlin (2014).

It can be seen that the discussion of this strategy is mostly focused on the policy itself or the impact on regional economic growth, less from the perspective of opening up, and one of this policy objectives is to improve the level of western development, which is essential to achieve through strengthening external ties. In the traditional sense, the definition of opening to the outside world still stays between countries. There are few researches on opening development between a micro region and all other regions, that is to say, few researches on opening to the domestic have been done at present. One reason is that it is not easy to define this indicator, and the other and most important reason is the unavailability of data. Based on this situation, this paper, from two perspectives of the opening to the outside world and to the domestic in the western region, discusses the changes of the opening up level in the western region under the background of the western development drive policy, and attempts to identify the net effect of this policy on the regional opening up to the outside world and to the domestic, so as to provide good policy suggestions for regional development.

\section{Methodology}

\subsection{Model building}

Based on the background of the western development drive policy, this paper discusses the policy effect of the influence of policy on the regional opening. In this paper, from the two perspectives of opening to the outside world and opening to domestic, we use the city panel data, combined with the 
DID(Differences-in-Differences) method to evaluate the policy effect. DID method can effectively eliminate the influence of other factors, so as to accurately identify the net effect of policy implementation, so this paper adopts this method to measure. In this paper, the DID model is established from the perspectives of opening to the outside world and opening to domestic as follows:

$$
Y i_{t}=\alpha_{0}+\alpha_{1} T D_{i t}+\sum \text { Control }_{i t}+\mu_{i}+\sigma_{t}+\varepsilon_{i t}
$$

$Y_{i t}$ represents city opening, including opening to the outside world and opening to the domestic, among them, opening to the outside world is measured by the proportion of fdi to GDP of each city, and opening to the domestic is measured by railway transportation volume; $\mathrm{TD}_{\mathrm{it}}$ represents the core explanatory variables, that is, is city the policy implementation area, intervention group takes 1 , and others 0 ; Controlit represents the control variables that can affect the opening up degree; $\mu_{\mathrm{i}}$ and $\sigma_{\mathrm{t}}$ represent the fixed effect of city and year respectively; $\varepsilon_{i t}$ is a random disturbance term.

The model (1) discusses the relevant information of policy effect evaluation from the perspectives of opening to the outside world and opening to the domestic, and the relationship between foreign investment and domestic investment is also worthy of attention in this policy background. Therefore, from the perspective of the linkage between foreign investment and domestic investment, this paper attempts to analyze the impact of domestic investment on foreign investment. Because there is no direct domestic data, this paper uses the railway transportation volume as an indicator to replace. The reason why this indicator is adopted is that the width of railway tracks in different countries is not uniform, while the width of domestic tracks in different countries is completely uniform, so that most of the bulk transactions of goods through railway transportation mode are carried out in China, which is also a good way to effectively identify the domestic capital represented by domestic trade. Therefore, this paper uses the railway transportation volume to replace domestic investment as follows:

$$
\text { Open }_{i t}=\beta_{0}+\beta_{1} \text { Inrailwayit }+\sum \text { Control }_{i t}+\mu_{i}+\sigma_{t}+\varepsilon_{i t}
$$

In the model (2), openitrepresents the opening to the outside world; and lnrailway ${ }_{i t}$ represents the opening to domestic. Controlit represents the control variables that can affect the opening; $\mu_{\mathrm{i}}$ and $\sigma_{\mathrm{t}}$ represent the fixed effect of city and year respectively; $\varepsilon_{i t}$ is a random disturbance term.

\subsection{Data sources}

This paper studies the data of China's prefecture-level cities from 1995 to 2015, all of which are from China's urban statistical yearbook and the official website of the National Bureau of Statistics. Some missing data also refer to the corresponding city Yearbook and province Yearbook. Because of the disunity of units in the indexes, this paper adjusts them by calculation.

\subsection{Index selection}

The explained variables in this paper include opening to the outside world and opening to the domestic. The former is measured by the proportion of fdi to GDP (open), and the latter by railway transportation volume (Inrailway). Because of the unavailability of domestic capital data, the measurement indicators of domestic capital are also replaced by railway transportation volume. The core explanatory variable in this paper is the implementation of the western development drive policy(TD). If the city is the intervention group of this policy, the value is 1 , and other cases are 0 . In addition, this paper also selects other factors that may affect the regional opening as control variables to be fixed, including regional per capita GDP (lnperGDP), fixed asset investment (lnfixedinvest), fiscal

revenue (fiscalrevenue), fiscal expenditure (Infiscalexpenditure), regional population (Intotalpopulation) and urbanization level (urbanization) to control.

\subsection{Model hypothesis}

This paper puts forward the model hypothesis from the perspective of policy effect evaluation and the relationship between domestic and foreign investment.

Hypothesis 1: the implementation of the policy may have a restrictive effect on the external development of the western region, but it may have a positive role in promoting the internal opening. 
Hypothesis 2: internal development may inhibit external development, that is, from the perspective of the relationship between domestic investment and foreign investment, domestic investment may have a "squeeze effect" on foreign investment.

\section{Results}

\subsection{The influence of the western development drive policy on the opening up of the western region}

Firstly, this paper makes a descriptive statistical analysis of variables, through the definition of variables and statistical observation, to prove the scientificity of variable selection. It can be seen that the standard deviation of the selected variables is small, which reflects the relatively stable characteristics of the data and can be used for regression. As shown in Table 1.

Table 1. Descriptive statistical analysis of variables.

\begin{tabular}{|c|c|c|c|c|}
\hline Variable & Variable Meaning & Computing Method & Mean Value & Std. Deviation \\
\hline Open & $\begin{array}{l}\text { Opening degree to } \\
\text { the outside world }\end{array}$ & Fdi/GDP & 1.5524 & 2.4861 \\
\hline Lnrailway & $\begin{array}{l}\text { Opening degree to } \\
\text { domestic }\end{array}$ & $\begin{array}{l}\text { Logarithm of railway } \\
\text { transportation volume }\end{array}$ & 6.1072 & 1.4278 \\
\hline $\mathrm{TD}$ & $\begin{array}{c}\text { Western } \\
\text { development drive } \\
\text { policy }\end{array}$ & $\begin{array}{l}\text { Whether it is the } \\
\text { implementation area of } \\
\text { the policy, virtual } \\
\text { variable }(0,1)\end{array}$ & 0.2974 & 0.4571 \\
\hline LnperGDP & $\begin{array}{c}\text { Per capita economic } \\
\text { development level }\end{array}$ & GDP / population & 9.5867 & 0.9449 \\
\hline Lnfixedinvest & $\begin{array}{l}\text { Fixed assets } \\
\text { investment }\end{array}$ & $\begin{array}{c}\text { Logarithm of fixed assets } \\
\text { investment }\end{array}$ & 64.5922 & 77.8621 \\
\hline Lnfiscalrevenue & Fiscal renevue & $\begin{array}{l}\text { Logarithm of regional } \\
\text { fiscal revenue }\end{array}$ & 12.1652 & 1.6320 \\
\hline Lnfiscalexpenditure & Fiscal expenditure & $\begin{array}{l}\text { Logarithm of regional } \\
\text { fiscal expenditure }\end{array}$ & 12.8505 & 1.6553 \\
\hline Lntotalpopulation & Total population & $\begin{array}{l}\text { Logarithm of total } \\
\text { regional population }\end{array}$ & 5.7664 & 0.7261 \\
\hline Urbanization & Urbanization level & $\begin{array}{l}\text { Urban population / total } \\
\text { population }\end{array}$ & 17.7304 & 16.0025 \\
\hline
\end{tabular}

Since the policy was first formally put forward in September 1999, this paper identifies 2000 as the year of implementation. Through the DID(Differences-in-Differences) method, this paper evaluates the influence of the western development drive policy on the regional opening up to the domestic and outside world. It can be seen that the (1) and (2) columns are the regression results without adding control variables. The implementation of the policy has a significant inhibitory effect on the western region's opening to the outside world, but it has a positive role in promoting the regional opening to domestic. Columns (3) and (4) are regression results after adding control variables. It can be seen that the results have not changed after adding control variables. Policies have a certain inhibition on opening to the outside world of the western region, but play a positive role in opening to domestic development. One of the purposes of this policy is to realize the transfer of surplus Industries in the eastern developed areas, improve the level of economic and social development in the western areas, and balance the regional development. Based on this, due to the influence of the preferential policy focus, compared with the impact on external development, the policy pays more attention to the impact of interregional development, so this may be one of the reasons for this result. As shown in Table 2. 
Table 2. DID regression results of the influence of the western development drive policy on the opening up of the western China.

\begin{tabular}{ccccc}
\hline Variable & Open & Lnrailway & Open & Lnrailway \\
\hline TD & $(1)$ & $(2)$ & $(3)$ & $(4)$ \\
Cons & $-1.1229^{* * *}$ & $0.3491^{* * *}$ & $-0.9206^{* * *}$ & $0.2863^{* * *}$ \\
& $(-6.92)$ & $(6.45)$ & $(-7.51)$ & $(5.33)$ \\
LnperGDP & $0.4355^{* * *}$ & $5.6605^{* * *}$ & 0.7331 & $-1.3203^{* *}$ \\
& $(3.45)$ & $(130.62)$ & $(0.59)$ & $(-2.06)$ \\
Lnfixedinvest & & & 0.1683 & $0.3971^{* * *}$ \\
& & & $(1.51)$ & $(6.89)$ \\
Lnfiscalrevenue & & & $0.0013^{* * *}$ & 0.0003 \\
& & & $(3.08)$ & $(1.18)$ \\
Lnfiscalexpenditure & & & $0.5949^{* * *}$ & -0.0023 \\
Lntotalpopulation & & & $(6.68)$ & $(-0.05)$ \\
Urbanization & & & $-0.6021^{* * *}$ & 0.0335 \\
& & & $(-6.27)$ & $(0.72)$ \\
City fixed effect & & & -0.1652 & $0.5558^{* * *}$ \\
Time fixed effect & & $(-1.62)$ & $(11.07)$ \\
$N$ & Yes & Yes & $-0.0192^{* * *}$ & $0.0084^{* * *}$ \\
R2 & Yes & Yes & $(-6.77)$ & $(5.78)$ \\
\hline
\end{tabular}

${ }^{1}$ Note: ${ }^{*}, * * * *$ are significant at the level of $10 \%, 5 \%$ and $1 \%$ respectively; In parentheses is the value of $\mathrm{t}$ statistic.

\subsection{A study on the "squeezing effect " of domestic investment on foreign investment}

From the results of the previous policy evaluation, we can see that the western development drive policy has certain hindrance to opening to the outside world, and has a positive role in promoting the opening to the domestic of the region, so what is the cause of this result worth further discussion. Foreign investment and domestic investment play an important role in the process of regional development. Clarifying the relationship between them will have a clearer perspective to grasp the different effects of the policy results. Therefore, this paper studies the relationship between regional domestic investment and foreign investment to grasp whether there is a "squeeze effect" between them, thus affecting the results. As domestic data cannot be obtained, railway transportation volume is used instead. The reason why this indicator is adopted is that the width of railway tracks in different countries is not uniform, while the width of domestic tracks in different countries is completely uniform, so that most of the bulk transactions of goods through railway transportation mode are carried out in China, which is also a good way to effectively identify the domestic capital represented by domestic trade. Through the results, we can see that the development of domestic investment in the western region has a restraining effect on foreign investment, which shows that the "squeeze effect" of regional capital exists. Although the result does not reach the significant expectation, it provides a certain explanation for the game between regional capitals, and also provides a new perspective for the different results of policy effect evaluation. The possible reason for the "squeeze effect" of domestic capital on foreign investment is that the original basis of regional capital inflow is different. There is still a large gap between the economic development of the western region and the eastern region of China. Therefore, the vast majority of foreign investment forces entering China are attracted by the eastern region of China. However, the western region has a weak attraction base for capital, so the total inflow of foreign investment in the western region is relatively low. Based on this fact, when the western development drive policy was implemented, domestic investment was active, which occupied the narrow space for foreign investment activities in the western region, resulting in the "squeeze" result. At the same time, the policy has a tilt effect on the transfer of surplus Industries from the east 
to the west, which intensifies the competition of capital activities in the west, and thus accelerates the emergence of "squeeze effect". As shown in Table 3.

Table 3. An analysis of the " squeezing effect " of capital.

\begin{tabular}{ccc}
\hline Variable & Open & Open \\
\hline Lnrailway & $(1)$ & $(2)$ \\
& -0.0472 & -0.0479 \\
cons & $(-1.31)$ & $(-1.30)$ \\
lnperGDP & $0.4916^{* *}$ & -0.0251 \\
& $(2.05)$ & $(-0.01)$ \\
Lnfixedinvest & & $0.3677^{* *}$ \\
& & $(2.32)$ \\
Lnfiscalrevenue & & $-0.0011^{*}$ \\
& & $(-1.79)$ \\
Lnfiscalexpenditure & & $0.2826^{* * *}$ \\
& & $(2.58)$ \\
Lntotalpopulation & & $-0.5449^{* * *}$ \\
Urbanization & & $(-4.49)$ \\
& & 0.0512 \\
City fixed effect & & $(0.34)$ \\
Time fixed effect & Yes & 0.0011 \\
N & Yes & $(0.25)$ \\
R2 & 985 & Yes \\
\hline & 0.2071 & Yes \\
& & 968 \\
& & 0.2380 \\
\hline
\end{tabular}

${ }^{1}$ Note: ${ }^{* * *}, * * *$ are significant at the level of $10 \%, 5 \%$ and $1 \%$, respectively; In parentheses is the value of $\mathrm{t}$ statistic.

\section{Discussion}

Through the analysis of the impact of the western development drive policy on regional opening up, this paper has a comprehensive understanding on the spillover effect of the policy implementation. However, the scientific discussion of the results and the test of method application need to be verified by the robustness test. Furthermore, this paper selects six indicators related to foreign development from 1999 to 2015, uses entropy method to make a comprehensive evaluation on the foreign development of western provinces, ranks the western provinces according to the evaluation results, and tries to discuss the heterogeneity of each province by comparing the opening up of western provinces. Due to space constraints, only the results of the five-year assessments in 2000, 2004, 2008, 2012 and 2015 are reported here.

\subsection{Robustness test}

Parallel trend test. The application of DID method must meet certain preconditions, that is, the intervention group and the control group have the same development trend. Therefore, this paper pushes forward the implementation time of the policy by two years (TD-1, TD-2). If the test results are significant, it shows that the development trend of intervention group and control group has been different before the implementation of the policy. Otherwise, it can be proved that they have parallel trend characteristics. It can be seen from the results that before the implementation of the policy in 2000 , the impact of the policy on the opening-up of the region was not significant, indicating that the natural trend of the development between the intervention group and the control group over time was the same, meeting the hypothesis of parallel trend. As shown in Table 4. 
Table 4. Parallel trend test.

\begin{tabular}{ccccc}
\hline Variable & Open & Lnrailway & Open & Lnrailway \\
\hline & $(1)$ & $(2)$ & $(3)$ & $(4)$ \\
TD & $-1.1678^{* * *}$ & $0.4181^{* * *}$ & $-0.9462^{* * *}$ & $0.3462^{* * *}$ \\
& $(-5.87)$ & $(6.36)$ & $(-6.32)$ & $(5.32)$ \\
TD-1 & -0.1377 & 0.1794 & -0.0919 & 0.1635 \\
& $(-0.37)$ & $(1.51)$ & $(-0.33)$ & $(1.42)$ \\
TD-2 & -0.0916 & 0.1714 & -0.0360 & 0.1362 \\
& $(-0.24)$ & $(1.41)$ & $(-0.13)$ & $(1.15)$ \\
-Cons & $0.4387^{* * *}$ & $5.6585^{* * *}$ & 0.7428 & $(-2.09)$ \\
& $(3.47)$ & $(130.55)$ & $(0.60)$ & Yes \\
Control variable & No & No & Yes & Yes \\
City fixed effect & Yes & Yes & Yes & Yes \\
Time fixed effect & Yes & Yes & Yes & 4445 \\
$\mathrm{~N}$ & 5376 & 4491 & 5344 & 0.1691 \\
R2 & 0.2116 & 0.1398 & 0.3379 & \\
\hline
\end{tabular}

${ }^{1}$ Note: ${ }^{* * *}, * * *$ are significant at the level of $10 \%, 5 \%$ and $1 \%$, respectively; In parentheses is the value of $\mathrm{t}$ statistic.

Counterfactual test. Whether the influence of the western development drive policy on the internal and external opening up includes other factors is also the focus of this paper. In order to identify this situation, this paper uses the regional counterfactual test to identify. In this paper, based on the number of cities in the western region, the approximate number is randomly selected from the whole sample, and the selected cities are used as virtual city samples (TDtotal) to get the policy impact, and the virtual effect is evaluated by the DID method. It can be seen that the results of policy evaluation are not significant, so other factors can be eliminated, that is, the results of regional opening completely come from the impact of the policy. As shown in Table 5.

Table 5. Counterfactual test.

\begin{tabular}{ccccc}
\hline Variable & Open & Lnrailway & Open & Lnrailway \\
\hline \multirow{2}{*}{ TDtotal } & $(1)$ & $(2)$ & $(3)$ & $(4)$ \\
& 0.0089 & 0.0148 & -0.0369 & 0.0051 \\
_Cons & $(0.14)$ & $(0.61)$ & $(-0.77)$ & $(0.22)$ \\
& $0.3658^{* * *}$ & $5.6703^{* * *}$ & 1.6073 & $-1.6372^{* *}$ \\
Control variable & $(2.89)$ & $(130.28)$ & $(1.29)$ & $(-2.55)$ \\
City fixed effect & No & No & Yes & Yes \\
Time fixed effect & Yes & Yes & Yes & Yes \\
N & Yes & Yes & Yes & Yes \\
R2 & 5376 & 4491 & 5344 & 4445 \\
\hline
\end{tabular}

${ }^{1}$ Note: ${ }^{*}, * * * *$ are significant at the level of $10 \%, 5 \%$ and $1 \%$, respectively; In parentheses is the value of $\mathrm{t}$ statistic.

Substitution variable test. This paper attempts to replace the index of openness to the outside world, and the purpose of regression again is to ensure the stability of the results. Because the scale of foreign-funded enterprises can represent the region attraction to foreign investment, and then represent the situation of regional opening to the outside world, this paper selects the total industrial output value of regional foreign-funded enterprises to measure the situation of regional opening to the outside world. Through the replacement variable regression, we get the same significant results as the main body of the article, which shows that the main body results are robust.

Elimination other policy interference test. In order to further eliminate the influence of other factors on the opening up of the western region and ensure the net effect of the western development drive policy on the opening up to the domestic and outside world, this paper further combs the other possible influences in the research time. In 2013, China put forward the "the Belt and Road" initiative. 
In this initiative, China's westward development has an important influence on the opening up of the western region. Therefore, this article eliminates the key provinces in the western region, which are related to the "the Belt and Road" initiative. The results of this paper are still significant after removing the samples, which shows that even after removing the policies or events that potentially affect the opening up of the western region, the impact of the western development drive policy on the opening up of the western region has not changed significantly, indirectly proving the reliability of the above results.

Addition extra covariates and missing variables test. In addition, in order to control the natural factors of regional change, this paper uses the method of Moser \& Voena (2012) for reference, adds the variable of regional change with time to the benchmark model. Due to the influence of degrees of freedom, this paper chooses to test at the provincial level. And variables are added to control, including the provinces trend of the primary term and the provinces trend of the secondary term that can be influenced by time. The results show that the results are still significant after considering these factors, indicating that the results are reliable. Furthermore, in order to ensure the scientific results, a series of missing variables are added to the benchmark model for testing, and the results are still significant.

\subsection{Comprehensive evaluation of the opening up of western provinces}

The absolute quantity of each index in western China's foreign development is slightly behind that of other regions in China, but its development speed is remarkable. Therefore, the accurate evaluation of each province opening up can better understand the characteristics of the heterogeneity within the region, so as to better balance the regional development. Based on this, this paper selects six indicators: the number of foreign-funded enterprises, total imports, total exports, the international tourism revenue, technology import funds for enterprises at scale and export delivery value of enterprises at scale to measure the external development of the western region, and evaluates the opening up of each province comprehensively by entropy method, and then obtains the ranking of the external development of each province. Due to the lack of data in Tibet Autonomous Region, there is no report here. Due to the lack of data in Tibet Autonomous Region, there is no report here. It can be seen from the comparison that the ranking of Sichuan province has always been in the first place, reflecting the strong vitality of its external development; subsequently, Chongqing city, Shaanxi province and Guangxi Zhuang Autonomous Region rank relatively high, among which Chongqing's ranking rises steadily with the change of external development, while Shaanxi province ranks opposite, and its ranking is in a state of fluctuation; Furthermore, Ningxia Hui Autonomous Region and Qinghai province are lower in the comprehensive ranking of the western region, and they have not been greatly improved, reflecting their weak external development strength and low external attraction. The details are shown in Table 6.

Table 6. Comprehensive evaluation ranking of western provinces' foreign development.

\begin{tabular}{cccccc}
\hline Province & $\mathbf{2 0 0 0}$ & $\mathbf{2 0 0 4}$ & $\mathbf{2 0 0 8}$ & $\mathbf{2 0 1 2}$ & $\mathbf{2 0 1 5}$ \\
\hline Sichuan & 1 & 1 & 1 & 1 & 1 \\
Inner Mongolia & 7 & 6 & 7 & 6 & 6 \\
Shaanxi & 2 & 2 & 10 & 10 & 4 \\
Ningxia & 10 & 10 & 3 & 2 & 10 \\
Chongqing & 4 & 5 & 8 & 8 & 2 \\
Gansu & 6 & 7 & 9 & 9 & 9 \\
Guizhou & 8 & 3 & 2 & 4 & 3 \\
Guangxi & 3 & 11 & 6 & 7 & 71 \\
Qinghai & 11 & 9 & 5 & 5 & 5 \\
Xinjiang & 9 & 4 & & & 7 \\
Yunnan & 5 & & 6 & & 5 \\
\hline
\end{tabular}

\section{Conclusion}

This paper discusses the net effect of the western development drive policy on the development of China's western region from the perspectives of internal and external opening. Through regression, 
it is found that the implementation of this policy has a restraining effect on the opening to the outside world in western region, but significantly improves the level of opening to domestic in the western region. In order to further explore the reasons for this result, this paper, through the grasp of the relationship between domestic and foreign capital in the western region, finds that there is a "squeeze effect", that is, regional domestic capital have a restraining effect on foreign capital. It can be seen that the implementation of this policy has a significant impact on the regional development, and achieve a policy effect, but at the same time, the policy's inhibition on regional opening to the outside world development is also the "double-edged sword" result of the implementation of this policy. In addition, this paper makes a comprehensive evaluation on the opening to the outside world development of the western provinces, and identifies the differences in regional heterogeneity, trying to grasp the development of the western provinces more accurately. Based on all the analysis, this paper puts forward relevant policy suggestions in order to better improve the level of high-quality opening to the outside world and opening to the domestic in the western region.

First of all, the government should vigorously improve the level of infrastructure in the western region and develop a variety of external connection channels. To expand opening to the outside world and opening to domestic development of the western region, first of all, we should strengthen and improve the regional infrastructure construction, including the improvement of the expansion of air, railway, highway and other means of transportation, broaden the regional trade channels to other provinces, and provide the carrier foundation for the province to "go out" and "bring in". At the same time, we should develop a variety of channels of foreign relations, including the combination of expanding the traditional trade mode and developing the emerging e-commerce mode. The development of e-commerce provides convenience for regional trade, and the mode of e-commerce trade is also constantly updating. The western region should strengthen the learning of the emerging mode and keep up with the development pace of the new era.

Secondly, the regional government should create a good environment for foreign investment, including policy preferences, system improvement and service efficiency improvement. The attraction of foreign capital, technology, talents and so on in the western region is weak, which results in the low total attraction of foreign investment. So, the western region can increase the preferential policy of foreign investment, and give the corresponding preferential policy support to drive the flow of capital to the western region. At the same time, the region should also improve system construction, improve the efficiency of government services, simplify procedures and processes, and provide a convenient service environment for attracting capital investment.

Finally, combined with regional location advantages and industrial advantages, we should seize the opportunity of "the Belt and Road" initiative to develop regional characteristic industries and increase the added value of products. The proposal of the "the Belt and Road" initiative is a favorable opportunity for the western region's external development, especially for the relatively backward provinces on opening up, such as Qinghai, Ningxia, Xinjiang and so on. In addition, the opening of China Railway express (CR express) has provided a strong support for the western region to open up the European market, which provides an excellent import and export opportunity for the western provinces, especially for the underdeveloped western provinces. These provinces have the development basis of characteristic agriculture, so we should base on this, combine agriculture with science and technology, extend the industrial chain, and make good use of this opportunity to realize the promotion of added value of agricultural industry.

Acknowledgments: This research was funded by Projects of the National Social Science Foundation of China, and the subject is the dilemma of global climate change negotiations and research on China's active response to participation in negotiations, grant number 16BZZ086. This research was also funded by China Western Economic Development Research Center of Northwest University, and the subject is the study on the spatial spillover effect of opening up in Western China on economic growth in the past 20 years, grant number XBZX18003. 


\section{References}

Bai Yongxiu, He Hao. 2019. Twenty years of western development: historical review, implementation results and development strategies. The Journal of Humanities: 11,52-62. https://doi.org/10.15895/j.cnki.rwzz.2019.11.008

Bai Yongxiu, Ren Baoping. 2000. The orientation and transformation of government functions in the development of the western region. Modern Economic Science: 04,11-16. https://doi.org/cnki:sun:djkx.2000.04.002

Cai HuaZhou. 2002. The effect of western development drive strategy in poor areas and policy suggestions. Southwest Finance:01,52-54. https://doi.org/cnki:sun:scjr.2002.01.020

Chen Taiming. 2017. Study on the difference of welfare effect in western development. Review of Investment Studies: 36,49-63. https://doi.org/cnki:sun:tzyj.2017.06.005

Gan Weiyu, Xu Xixiong, Yi Juan. 2011. The periodical evaluation and improvement countermeasure of the implementation effect of China's western development strategy. Economic Geography:31,40-46. https://doi.org/10.15957/j.cnki.jjdl.2011.01.014

Kong Yang, He Weijun, Qian Chaohui, Tan Jiangtao. 2018. Assessment of the net effect of China's western development policy. Statistics Decision: 34,91-95. https://doi.org/10.13546/j.cnki.tjyjc.2018.24.022

Li Hui. 2006. The evaluation of the policy effect of the western development drive strategy. Journal of Lanzhou Commercial College: 03,70-74. https://doi.org/10.3969/j.issn.1004-5465.2006.03.016

Lin Jianhua, Ren Baoping. 2009. Performance evaluation of the western development strategy for 10 years :1999 2008. Research on Development: 01,48-52. https://doi.org/ 10.13483/j.cnki.kfyj.2009.01.006

Liu Ruiming, Zhao Renjie. 2015. Western development drive policy: growth driven or policy trap - based on PSMDID method. China Industrial Economics: 06,34-45. https://doi.org/10.19581/j.cnki.ciejournal.2015.06.004

Peng Hui, Zhang Lishu.2009. Comprehensive evaluation of the implementation effect of the western development drive strategy. Science E Technology Progress and Policy:10,46-50. https://doi.org/cnki:sun:kjjb.2009.10.012

Peng $\mathrm{Xi}$, Chen Zhongchang. 2016. The evaluation of the policy effect on the western development drive policy. China Population, Resources and Environment:26,136-144. https://doi.org/10.3969/j.issn.1002-2104.2016.03.017

Ren Baoping, Zhang Qian. 2019. Achievements, experience and transformation of economic development in the western region in the past 20 years. Journal of Shaanxi Normal University(Philosophy and Social Sciences Edition): 48,46-62. https://doi.org/ 10.15983/j.cnki.sxss.2019.0721

Ru Shaofeng, Zhou Zikai. 2019. The net effect of policy and the high quality development of economy in Western China in the past 20 years - based on PSM-DID method. Journal of Shaanxi Normal University(Philosophy and Social Sciences Edition):48,63-75. https://doi.org/10.15983/j.cnki.sxss.2019.0722

Shao Chuanlin. 2014. The measure of local government scale expansion effect from the perspective of western development drive strategic -- an empirical study based on the multiple difference method. Journal of Central South University(Social Science): 05,160-165. https://doi.org/10.3969/j.issn.1672-3104.2014.05.027

Tan Zhouling, Cheng Bao. 2018. An analysis of the net policy effect of the western development drive policy. China Population, Resources and Environment:28,169-176. https://doi.org/10.12062/cpre.20170718

Wang Xiaoli, Li Nana, Zhu Jiashu, Li Qiang. 2019. Western development: natural growth or policy effect-based on synthetic control method. Resource Development \&Market: 35,463-469. https://doi.org/10.3969/j.issn.10058141.2019.04.004

Wang Yongjing, Ge Wenfang. 2016. The evaluation of the implementation effect of the western development drive strategy and policy suggestions. Xinjiang State Farms Economy:04,60-65. https://doi.org/cnki:sun:nong 2016.04.012

Wei Houkai, Sun Chengping. 2004. Evaluation of the implementation effect of the western development drive strategy in China. Research On Development: 03,21-25. https://doi.org/10.13483/j.cnki.kfyj.2004.03.007

Wei Houkai, Zhao Yong. 2014. The implementation of western development strategy assessment and policy recommendations. Research on Development: 01,1-7. https://doi.org/10.13483/j.cnki.kfyj.2014.01.001

Zeng Kunsheng. 2002. Analysis of policy effect of western development drive strategy on the combination of central and western regions. Reformation $\mathcal{E}$ Strategy: 09,31-35.https://doi.org/10.16331/j.cnki.issn1002736x.2002.09.008

Zhou Duanming, Zhu Yunxi, Wang Chunting. 2014. Western development, regional convergence and economic policy choice. Contemporary Economic Research:05,30-36. https://doi.org/cnki:sun:ddjj.2014-05-005 